\title{
Brazilian guidelines for endovascular treatment of patients with acute ischemic stroke
}

\section{Diretrizes brasileiras para o tratamento endovascular de pacientes com acidente vascular cerebral isquêmico agudo}

Octávio Marques Pontes-Neto*1, Pedro Cougo*1, Sheila Cristina Ouriques Martins², Daniel G. Abud', Raul G. Nogueira ${ }^{3}$, Maramélia Miranda 4 , Luiz Henrique de Castro-Afonso', Leticia C. Rebello5, José Guilherme M. Pereira Caldas 6 , Rodrigo Bazan?, Daniel C Bezerra ${ }^{8}$, Marco Tulio Rezende', Gabriel R. de Freitas ${ }^{10,11}$, Alexandre Longo ${ }^{12}$, Pedro Magalhães ${ }^{12}$, João José Freitas de Carvalho ${ }^{13}$, Francisco José Montalverne ${ }^{13}$, Fabricio Oliveira Lima ${ }^{13}$, Gustavo H. V. Andrade ${ }^{14}$, Ayrton R. Massaro ${ }^{15}$, Jamary Oliveira-Filho ${ }^{16}$, Rubens Gagliardi17, Gisele Sampaio Silva ${ }^{18,19}$

\begin{abstract}
These guidelines are the result of a joint effort from writing groups of the Brazilian Stroke Society, the Scientific Department of Cerebrovascular Diseases of the Brazilian Academy of Neurology, the Brazilian Stroke Network and the Brazilian Society of Diagnostic and Therapeutic Neuroradiology. Members from these groups participated in web-based discussion forums with predefined themes, followed by videoconference meetings in which controversies and position statements were discussed, leading to a consensus. This guidelines focuses on the implications of the recent clinical trials on endovascular therapy for acute ischemic stroke due to proximal arterial occlusions, and the final text aims to guide health care providers, health care managers and public health authorities in managing patients with this condition in Brazil.
\end{abstract}

Keywords: stroke; endovascular procedures; guideline; thrombectomy.

\section{RESUMO}

Estas diretrizes são o resultado de um esforço conjunto de membros da Sociedade Brasileira de Doenças Cerebrovasculares (SBDCV), Departamento científico de Doenças Cerebrovasculares da Academia Brasileira de Neurologia (ABN), Rede Brasil AVC (RBAVC) e da Sociedade Brasileira de Neurorradiologia Diagnóstica e Terapêutica (SBNR). Membros destas 4 entidades participaram de fórum de discussões por internet de temas pré-definidos, seguidos de encontros de videoconferência para discussão de pontos controversos e das recomendações, em busca de um consenso final. Estas diretrizes tem seu foco sobre as implicações dos recentes ensaios clínicos de tratamento endovascular do acidente vascular cerebral (AVC) isquêmico agudo relacionado a oclusão de artérias proximais. 0 texto final foi elaborado para servir de orientação no manejo destes pacientes AVC isquêmico pelos diferentes profissionais de saúde, gestores de saúde pública e de saúde complementar no Brasil.

Palavras-chave: acidente vascular cerebral; procedimentos endovasculares; guia; trombectomia.

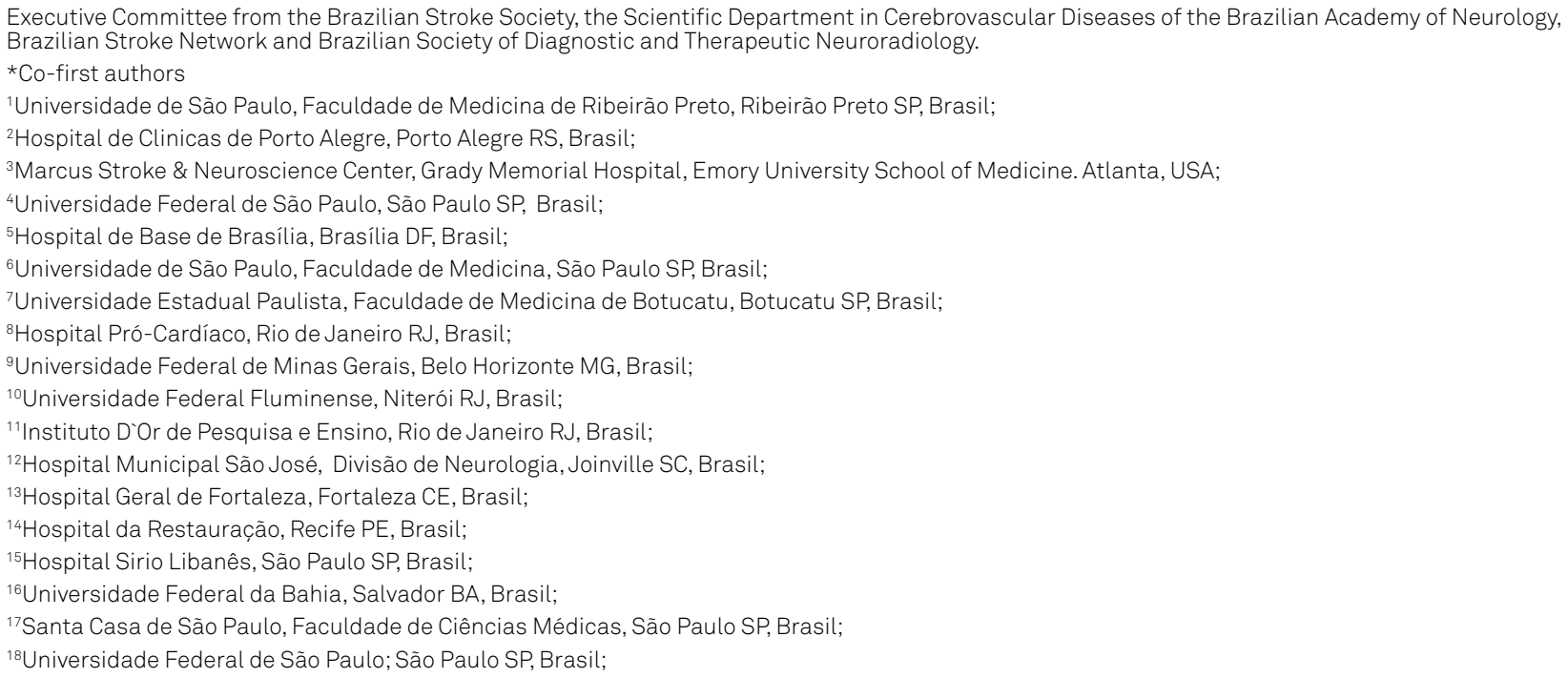


These guidelines are the result of a joint effort from writing groups of the Brazilian StrokeSociety, theScientific Department of Cerebrovascular Diseases of the Brazilian Academy of Neurology, the Brazilian Stroke Network and the Brazilian Society of Diagnostic and Therapeutic Neuroradiology. Those societies have been involved in treatment opinions and educational projects related to cerebrovascular diseases in Brazil. Members from the groups above participated in web-based discussion forums with pre-defined themes, followed by videoconference meetings in which controversies and position statements were discussed, leading to a consensus. This guidelines focuses on the implications of the recent clinical trials on endovascular therapy for acute ischemic stroke (AIS) due to proximal arterial occlusions (PAO), and the final text aims to guide specialists and non-specialists in stroke care in managing patients with this condition.

The final recommendations are classified based on recommendation grade and evidence level. Recommendation grades are divided in three main categories, based on the level of certainty that the treatment is beneficial - certainly beneficial, of uncertain benefit, and certainly not beneficial or even harmful - and its entailing proposition for clinical care. Levels of evidence indicate the quality of the scientific evidence that supports the recommendation. High levels of recommendation refer to results from good quality randomized clinical trials that have been reproduced, from meta-analysis of good quality clinical trials, and from a single clinical trial of good quality. Recommendations from observational studies are classified as weak. We specify a weak level of evidence for subgroups of patients, which are under-represented in good quality clinical trials, and which have not been resolved by appropriate subgroup analysis; if such analysis has been performed, then the recommendation qualifies as high level.

It is worth mentioning that recommendations from guidelines - as well as data from clinical trials - apply to qualifying groups of patients, but not necessarily to individual patients. Therefore, the recommendations serve as guidance to bedside decision-making and do not substitute for patient-centered clinical reasoning.

\section{RECOMMENDATION GRADES}

1) 1) therapy is beneficial and is recommended.

2a) therapy is probably beneficial and should be considered.

2b) therapy is possibly beneficial and might be considered.

3) the treatment is not beneficial or may be harmful and is not recommended.

\section{EVIDENCE LEVELS}

A) (high): the recommendation is supported by more than one randomized clinical trial of good quality, OR by a well-performed meta-analysis.
B) (moderate): the recommendation is supported by only one randomized clinical trial of good quality.

$\mathrm{Cl}$ )(weak): the recommendation applies to under-represented subgroups of one or more randomized clinical trials that have not been adequately resolved in subgroup analysis, and for which the panel believes that there is sufficient clinical and biological reasoning to support a recommendation.

C2) (weak): the recommendation is supported by observational or non-randomized studies.

E) (expert opinion): the panel considers that there is sufficient clinical and biological reasoning to support a recommendation, in spite of the absence of good quality clinical trials and observational studies.

\section{Endovascular reperfusion therapy}

About one third of patients with AIS present with an occlusion of a large, proximal artery of the brain circulation ${ }^{1}$. Recently, endovascular treatment has been shown to improve functional outcome in five randomized clinical trials of selected patients with AIS associated with PAO of the anterior circulation ${ }^{2,34,5,5,7}$. A summary of core design features and results is presented in the Table. These trials had important differences in design, including eligibility criteria, which poses some relevant issues for interpretation and implementation of practice. However, as a common denominator, they all conveyed a clear message that early endovascular treatment with high rates of successful reperfusion leads to better clinical outcome with very large effect sizes. The number needed to treat (NNT) to achieve functional independence at three months after the stroke varied from 7.4 in the Multicenter Randomized Clinical Trial of Endovascular Treatment for Acute Ischemic Stroke in the Netherlands (MR CLEAN) - a less selective, pragmatical trial - to as low as 3.2 in the Extending the Time for Thrombolysis in Emergency Neurologic Deficits - Intra-arterial (EXTEND-IA), a penumbral mismatch-based, highly selective trial. The combined analysis of these trials shows that the NNT for reduced disability of one point on the modified Rankin Scale was 2.6, and 5.1 for achieving functional independency ${ }^{8}$. Altogether, these trials should bring endovascular treatment - when performed under selected circumstances - to the standard-of-care as recommended by a high level of evidence. Moreover, the combined results of these trials suggest that the therapeutic benefit is dependent on well-organized stroke care, rapid initiation of the endovascular procedure and high rates of early and successful reperfusion.

These guidelines aim to give recommendations addressing the question of whether endovascular treatment can improve long-term functional outcome in patients with an AIS caused by a PAO, when compared to standard clinical treatment. Three main issues arise when translating these results into guideline recommendations: (1) there were subgroups of patients that, despite being included in most of the protocols, were significantly underrepresented in the final population; 
Table. Selected features of positive trials on endovascular reperfusion therapy for acute ischemic stroke (AIS).

\begin{tabular}{|c|c|c|c|c|c|c|c|}
\hline Variable & PAO actual location & $\begin{array}{l}\text { Age, } \\
\text { yo. }\end{array}$ & $\begin{array}{l}\text { NIHSS } \\
\text { eligibility }\end{array}$ & $\begin{array}{l}\text { Neuroimaging eligibility } \\
\text { (besides proof of a PAO) }\end{array}$ & IVTPA & $\begin{array}{c}\text { Time } \\
\text { window }\end{array}$ & $\begin{array}{l}\text { Stent } \\
\text { retrievers }\end{array}$ \\
\hline \multirow{4}{*}{ MR CLEAN } & IC ICA + M1 27\% & \multirow{4}{*}{$\geq 18$} & \multirow{4}{*}{$\geq 2$} & \multirow{4}{*}{ None } & \multirow{4}{*}{$89 \%$} & \multirow{4}{*}{$6 \mathrm{~h}$} & \multirow{4}{*}{$97 \%$} \\
\hline & M1 64\% & & & & & & \\
\hline & M2 8\% & & & & & & \\
\hline & Associated EC ICA 29\% & & & & & & \\
\hline \multirow{4}{*}{ EXTEND-IA } & IC ICA 31\% & \multirow{4}{*}{$\geq 18$} & \multirow{4}{*}{ None } & Perfusion mismatch on CTP & \multirow{4}{*}{ Mandatory } & \multirow{4}{*}{$6 \mathrm{~h}$} & \multirow{4}{*}{$\begin{array}{l}\text { Solitaire FR } \\
\text { mandatory }\end{array}$} \\
\hline & M1 57\% & & & Tissue at risk as Tmax $>6 s$ & & & \\
\hline & M211\% & & & Infarct core as CBF $<50 \%$ normal & & & \\
\hline & & & & $\begin{array}{c}\text { Mismatch: mismatch ratio }>1.2 \text { and } \\
\text { mismatch volume }>10 \mathrm{~mL} \text { and ischemic } \\
\text { core }<70 \mathrm{~mL}\end{array}$ & & & \\
\hline \multirow{5}{*}{ ESCAPE } & $I C A+M 128 \%$ & \multirow{5}{*}{$\geq 18$} & \multirow{5}{*}{$>5$} & ASPECTS $\geq 6$ on CT & \multirow{5}{*}{$73 \%$} & \multirow{5}{*}{$12 \mathrm{~h}$} & \multirow{5}{*}{$86 \%$} \\
\hline & M1/all M2 71\% & & & On CTA or CTP, excluded if: & & & \\
\hline & M2 2\% & & & $\begin{array}{c}\text { Poor collaterals on }>50 \% \text { of MCA } \\
\text { territory }\end{array}$ & & & \\
\hline & \multirow[t]{2}{*}{ Associated EC ICA 13\% } & & & OR low CBV/CBF: ASPECTS $<6$ & & & \\
\hline & & & & OR low CBV/CBF > 1/3 of MCA territory & & & \\
\hline \multirow{3}{*}{ SWIFT-PRIME } & IC ICA $18 \%$ & \multirow{3}{*}{$\begin{array}{c}18- \\
80\end{array}$} & \multirow{3}{*}{$8-29$} & \multirow{3}{*}{$\begin{array}{c}\text { Eligible if ASPECTS } \geq 6 \text { or ischemic } \\
\text { signs on }<1 / 3 \text { of MCA territory on CT } \\
\text { or DWI }\end{array}$} & \multirow{3}{*}{ Mandatory } & \multirow{3}{*}{$6 \mathrm{~h}$} & \multirow{3}{*}{$\begin{array}{l}\text { Solitaire FR } \\
\text { mandatory }\end{array}$} \\
\hline & M1 68\% & & & & & & \\
\hline & M2 14\% & & & & & & \\
\hline \multirow{4}{*}{ REVASCAT } & IC ICA + M1 25\% & \multirow{4}{*}{$\begin{array}{c}18- \\
80\end{array}$} & \multirow{4}{*}{$>5$} & \multirow{4}{*}{ Eligible if ASPECTS $\geq 6$ on CT } & \multirow{4}{*}{$68 \%$} & \multirow{4}{*}{$8 \mathrm{~h}$} & \multirow{4}{*}{$\begin{array}{l}\text { Solitaire FR } \\
\text { mandatory }\end{array}$} \\
\hline & M1 65\% & & & & & & \\
\hline & Single M2 10\% & & & & & & \\
\hline & Associated EC ICA 19\% & & & & & & \\
\hline
\end{tabular}

PAO: proximal arterial occlusions; NIHSS: National Institutes of Health Stroke Scale; IV TPA: intravenous tissue plasminogen activator; MR CLEAN: multicenter randomized clinical trial of endovascular treatment for acute ischemic stroke in the Netherlands; EXTEND-IA: extending the time for thrombolysis in emergency neurological deficits - intra-arterial; ESCAPE: endovascular treatment for small core and anterior circulation proximal occlusion with emphasis on minimizing CT to recanalization times; SWIFT-PRIME: solitaire with the Intention for thrombectomy as primary endovascular treatment; REVASCAT: randomized trial of revascularization with solitaire FR device versus best medical therapy in the treatment of acute stroke due to anterior circulation large vessel occlusion presenting within eight hours of symptom onset; IC ICA: intracranial segment of the internal carotid artery; M1 and M2: first and second segments of the MCA; EC ICA: extracranial segment of the internal carotid artery; Tmax: time to maximum; CBF: cerebral blood flow; ASPECTS: Alberta stroke program early CT score; CT: computed tomography; MCA: middle cerebral artery; CTA: CT angiography; CTP: CT perfusion; CBV: cerebral blood volume; DWI: diffusion weighted imaging; Solitaire FR: solitaire stent-retriever device.

(2) due to differences in design, there were subgroups that were not reproduced in more than one study; (3) and these results reflect organized, optimal care of selected patients treated in specialized centers. Therefore, this guideline will balance its recommendations favoring core features shared by them, while noting subgroups that deserve more careful consideration. Fortunately, two meta-analyses with patient-level data have addressed many of these questions regarding specific subgroups ${ }^{8,9}$. We will also emphasize the requirements for stroke care organization and performance monitoring to improve the implementation of endovascular treatment. Some considerations regarding eligibility, intervention and implementation are shown below. Future studies are warranted to answer remaining issues regarding efficacy among subgroups, as well as real-world clinical effectiveness and cost-effectiveness in different systems of care. Finally, the efficacy of endovascular treatment has been demonstrated only in the presence of high-level infrastructures (e.g. last-generation devices, fast clinical and neuroimaging workflows, highly specialized personnel) and optimized systems of care, thus its safety, efficacy, and cost-effectiveness in developing countries will likely require further validation.

In Brazil, endovascular treatment carries some specific implications. Despite being one of the leading causes of mortality in the country, stroke has been severely neglected, with very poor stroke awareness in the population and very low rates of treatment with intravenous thromboly$\operatorname{sis}^{10,11}$. Unfortunately, Brazil is a country of great economic inequalities, with some stroke units in the private and public hospitals, especially in the wealthier regions of the country, presenting similar thrombolysis rates to those of tertiary stroke centers of developed countries ${ }^{11,12,13}$. These services routinely perform endovascular treatment for stroke and were able to develop a triage and quality control system, with some centers even being certified by international institutions such as the Joint Commission to 
the Canadian Stroke Network ${ }^{14}$. In more recent years, improvements in acute stroke care and prevention have led to a decrease in stroke mortality and stroke incidence ${ }^{15,16,17}$. The emergence of endovascular treatment as a standardof-care comes in the context of an increasing number of stroke centers ${ }^{18}$. The necessity of making intravenous thrombolysis widely available has been a fundamental reason for this increase. We believe that the implementation of endovascular treatment in the Brazilian healthcare system could serve as an additional driving force to further increase the national stroke network, both in size and in spectrum of complexity ${ }^{19,20}$.

\section{Considerations on patient selection and endovascular intervention}

The only core eligibility criterion equally present among all trials was the presence of a target PAO - defined as modified Thrombolysis in Cerebral Ischemia (TICI) score of 0-1 - of the anterior circulation assessed by computed tomography angiography (CTA) or magnetic resonance imaging angiography (MRA) before endovascular treatment was indicated. This represents a major difference from the prior clinical trials on endovascular treatment, which used clinical criteria, such as the National Institute of Health Stroke Scale (NIHSS) score, and failed to demonstrate clinical benefit $^{21,22,23}$. In the Interventional Management of Stroke III trial (IMS-3), patients were mainly selected based on an NIHSS $\geq 10$, and one third of them eventually did not have a target occlusion on catheter angiography. Cut-off values of NIHSS scores with the highest accuracy for detecting PAO (scores from 10 to 14) still present false-negative rates $>20 \%$, and scores with sufficient sensitivity to detect $>90 \%$ of patients with PAO (NIHSS from 1 to 5) would result in sending almost every patient to catheter angiography ${ }^{1,24}$. Therefore, vessel imaging by CTA or MRA is highly recommended for endovascular treatment indication ${ }^{23}$.

Transcranial Doppler (TCD) has been shown to have good accuracy for detecting PAO and might be useful in patients with AIS who have contraindications to CTA and MRA ${ }^{25,26}$. However, this method was not systematically used to select patients in a clinical trial of endovascular treatment, and its use in the AIS setting demands a high level of expertise.

Regarding the site of the target occlusion, the majority of patients included in the recent trials had an M1 segment middle cerebral artery (MCA) occlusion (57-68\%), followed by top-of-carotid occlusions [intracranial internal carotid artery (ICA), with or without M1 MCA; 18-31\%] and M2 segment MCA occlusions (2-14\%). The Endovascular Treatment for Small Core and Anterior Circulation Proximal Occlusion with Emphasis on Minimizing CT to Recanalization Times (ESCAPE) (13\%), the Randomized Trial of Revascularization with Solitaire FR Device versus Best Medical Therapy in the Treatment of Acute Stroke Due to Anterior Circulation Large Vessel Occlusion Presenting within Eight Hours of Symptom
Onset (REVASCAT) (19\%) and MR CLEAN (29\%) allowed for randomization of patients with extracranial ICA occlusions $^{2,4,6}$. Two meta-analyses have confirmed benefit for patients with $\mathrm{M} 1$ and ICA occlusions, but not for patients with M2 occlusions ${ }^{8,9}$. However, the number of patients with M2 occlusions was small (98 among 1,287 enrolled), and there was no interaction between treatment efficacy and PAO location. Although more studies will be necessary to address this issue, we believe that it is likely that early and successful reperfusion could be beneficial in patients with M2 occlusions.

Clinical deficit requirements for eligibility in the trials were not homogeneous. The majority of patients enrolled in all trials had high NIHSS scores, as should be expected. Patients with minor clinical deficits who have a PAO have a higher likelihood of suffering clinical deterioration, and could still benefit from reperfusion ${ }^{27,28}$. Based on the current data and the divergent clinical deficit criteria used in the trials, it is not possible to determine an unambiguous cut-off on the NIHSS for indicating endovascular treatment. More importantly, waiting for persistence of clinical symptoms after the full dose of intravenous tissue plasminogen activator (IV TPA) - "failure of IV TPA" - was not a requirement in order to assess for thrombectomy eligibility and randomization, and adoption of such criterion would delay treatment initiation. The benefit of endovascular therapy was confirmed in patients older than 80 years old ${ }^{8.9}$. Although the presence of a modified Rankin Scale of $\leq 1$ was required for enrollment in all trials, it seems reasonable to consider that patients with prior mild to moderate disability could still benefit from therapy.

Time to treatment was defined in the trials as the period from symptom onset (defined as the time last seen well) to groin puncture. In three of the five trials, patients were eligible if endovascular treatment was to be initiated no later than six hours ${ }^{2,3.5}$. The REVASCAT trial would treat patients up to eight hours, requiring the presence of a small infarct on non-contrast computed tomography $(\mathrm{CT})^{6}$. The ESCAPE trial would treat patients until 12 hours after symptom onset based on the use of CT and CTA to determine the presence of a small infarct and good collateral status ${ }^{4}$. However, in spite of these differences, the great majority of patients included in all trials were treated within the early six-hour window [median onsetto-groin in minutes: 185 (ESCAPE) to 269 (REVASCAT)]. In the SWIFT-PRIME trial, the rate of functional independency decreased by $10 \%$ to $20 \%$ for every hour of treatment delay in the intervention $\mathrm{arm}^{29}$. Both meta-analyses showed that the subgroup of patients randomized after five hours benefited from therapy, but it is still unclear whether treatment initiated after six hours is beneficial ${ }^{8,9}$.

Except for MR CLEAN, all trials explicitly required (at least) the presence of a small infarct core on admission neuroimaging, most commonly defined by an Alberta Stroke Program Early CT Score (ASPECTS) $\geq 6$ on either CT or diffusion-weighted magnetic resonance imaging (MRI). 
The MR CLEAN trial did not explicitly state any contraindications based on admission ischemic findings on CT. However, the median ASPECTS score of treated patients in this trial was 9 (interquartile range: $7-10$ ). Ninety-two subjects had ASPECTS from 5-7 and only 28 from 0-4. In MR CLEAN, there was no interaction between treatment effect and ASPECTS strata (0-4, 5-7 and 8-10), however the study was likely underpowered to detect differences in the $0-4$ subgroup $^{30}$. In total, 121 patients had ASPECTS from 0-5 in the five trials, and the benefit in this subgroup could not be confirmed in meta-analysis ${ }^{8}$. We believe that until more data is available on this matter, patients with large infarct cores should not be treated with endovascular treatment.

Additional criteria were used in the other trials. All patients evaluated in EXTEND-IA used the RAPID evaluation as an inclusion criterion to determine the presence of penumbral mismatch on CT perfusion ${ }^{31}$. The SWIFT-PRIME also used the same strategy for the first 71 of 196 patients but later adopted the ASPECTS core criteria to ensure quicker therapy and higher enrollment. The ESCAPE trial adopted the presence of good collateral status or penumbral mismatch as an additional criterion in addition to a small infarct core. Trials using these additional criteria (e.g. collateral or perfusion imaging) might have selected patients more likely to benefit from therapy, but might have excluded patients who could still benefit from endovascular treatment. The presence of either penumbral mismatch (EXTEND-IA) or good collateral flow (ESCAPE) should not be considered mandatory for treatment indication, but might be used as ancillary data for individualized decisions.

The SWIFT-PRIME and EXTEND-IA only included patients who had received intravenous thrombolysis according to standards-of-care. Patients not receiving intravenous thrombolysis due to contraindications were $11 \%, 27 \%$ and $32 \%$ in MR CLEAN, ESCAPE and REVASCAT trials. Subgroups analysis later confirmed that patients not receiving IV TPA also benefit from endovascular treatment ${ }^{8,9}$.

Mechanical thrombectomy with stent retrievers was the mandatory endovascular treatment technique in SWIFT-PRIME, EXTEND-IA and REVASCAT, and was also used for the vast majority of patients in MR CLEAN (97\%) and ESCAPE (86\%). This choice was driven by the findings of SWIFT and TREVO-2, two head-to-head randomized clinical trials comparing the reperfusion performance of stent retrievers against the MERCI device, where stent retrievers yielded a four-times higher chance of post-procedure reperfusion and higher rates of good clinical outcome ${ }^{32,33}$. Indeed, prior trials that did not show benefit of endovascular treatment used other first generation mechanical thrombectomy devices (mainly the MERCI device) or intra-arterial injection of $\mathrm{TPA}^{21,22,34}$. One assumed reason for the absence of clinical benefit in those earlier trials was the low rate of successful reperfusion. Stent retrievers should be the first choice of device whenever considered feasible by the treating interventionist.
The angiographic goal of endovascular radiation therapy should be complete or near-complete reperfusion, defined as a grade of $2 b$ or 3 in the modified Thrombolysis in Brain Ischemia (mTICI) score.

The type of anesthesia used during endovascular treatment is still a matter of debate. It has been described that the use of general anesthesia results in increased intensive care unit stay, larger infarct volumes and worse clinical outcomes, when compared to conscious sedation in observational studies ${ }^{35}$. In the MR CLEAN trial, patients who underwent general anesthesia had longer door-to-groin times and worse functional outcomes, with no significant benefit compared to controls. The SIESTA trial was a single-center, randomized, open-label trial with blinded endpoint evaluation comparing conscious sedation with intubation with general anesthesia performed by a neurointensivist in patients receiving endovascular treatment. There was no difference between groups in the primary endpoint of early neurological improvement in the NIHSS score after 24hours. (Oral abstract at the European Stroke Organization conference, 2016) Given the limitations of this single-center trial, further clinical trials addressing the use of general anesthesia or conscious sedation are still necessary.

\section{Generalizability and institutional implementation}

The contemporary trials on endovascular treatment were all conducted in comprehensive stroke centers with experience in treating patients with AIS in developed nations. It should be noted that the positive results also reflect very fast and early treatment initiation (the median CT to groin puncture time in the ESCAPE trial was 51 minutes), very high rates of successful reperfusion and low rates of complications. The generalizability of these results requires that endovascular treatment should be performed in experienced stroke centers. Also, quality improvement initiatives have been shown to improve important metrics of stroke care. With the establishment of endovascular treatment as a standard of care in anterior circulation ischemic stroke with PAO and its increased and widespread use, it is important that institutional initiatives are held to monitor and improve procedural metrics of safety and efficacy, including key metrics such as time of initiation of therapy and rate of complete reperfusion. Moreover, the design of local protocols should reflect local resources and expertise. The success of the implementation of endovascular treatment on public and private healthcare systems relies on careful planning and assessment of local resources, and the organization of a stroke network that is able to identify and refer patients to the appropriate comprehensive stroke center.

\section{Recommendations}

1) Endovascular treatment is recommended for adult patients with AIS due to a PAO in the anterior circulation with a significant neurologic deficit measurable on the NIHSS stroke scale and a relatively small infarct core on baseline 
neuroimaging (i.e., ASPECTS $\geq 6$ ) who can have their treatment initiated within six hours of symptom onset and prior treatment with IV TPA (Recommendation: 1-A).

2) Even if endovascular treatment is indicated, IV TPA is recommended prior to endovascular treatment in eligible patients according to previously published guidelines. (Recommendation 1-A)

3) Endovascular treatment should neither preclude nor delay intravenous thrombolysis in patients who are candidates for both treatments. (Recommendation: 1-A). Also, presumed "failure" of IV TPA should not be waited for in order to indicate or initiate endovascular treatment. (Recommendation: 1-A). When eligible, endovascular treatment is recommended even in patients with contra-indication to IV TPA (Recommendation: 1-A).

4) Patients eligible for endovascular treatment should be treated as soon as possible, and the groin puncture should be performed within six hours of symptom onset (Recommendation: 1-A). It is uncertain whether treatment initiated after six hours may be beneficial for selected patients (Recommendation: 2b-C1).

5) Selection of patients for endovascular treatment should be based on a clinical diagnosis of AIS due to a documented PAO confirmed by CTA, MRA or digital subtraction angiography. (Recommendation: 1-A). Transcranial doppler performed by skilled examiners might be useful for detecting PAO in this setting, in cases of contraindications for or unavailability of CTA and/or MRA (Recommendation: 2b-C2).

6) Occlusion of the M1 segment of the MCA or the terminal ICA are considered eligible PAO (Recommendation: 1-A). Patients with occlusions of the M2 MCA segment might be considered for treatment (Recommendation: 2b-C1). Patients with an associated extracranial ICA occlusion also benefit from therapy (Recommendation: 1-A), however it is not established whether revascularization of the cervical ICA must be performed at the same time as the target intracranial thrombectomy.

7) Age should not be used as an isolated criterion for excluding patients from therapy (Recommendation: 1-A). The severity of the clinical deficit and the presence of prior disability should not be used as absolute contraindications for therapy, and clinical judgment is necessary when taking these issues into account (Recommendation: 3-E).

8) A non-contrast CT scan or diffusion-weighted MRI should be done to assure ischemic type and that the baseline infarct core is limited (ASPECTS $\geq 6$ ) (Recommendation: 1-A). Penumbral mismatch assessment on perfusion imaging or collateral grading on CTA can help select patients in individualized decision making (Recommendation: 2a-A), but are not mandatory for treatment indication.

9) New generation devices like stent retrievers should be the primary choice of technique for endovascular treatment (Recommendation: 1-A). The therapeutic goal of endovascular treatment should be of complete or near-complete reperfusion (TICI 2b-3). (Recommendation: 1-A). If deemed useful in order to achieve successful reperfusion by the treating interventionist, proximal balloon guiding catheters, large bore aspiration catheters or alternative techniques (intra-arterial thrombolysis, alternative devices, etc.) might be considered at the discretion of the interventionist (Recommendation: 2b-C1).

10) Conscious sedation, as opposed to general anesthesia, might be beneficial in patients undergoing endovascular treatment in improving the chances of good clinical outcome (Recommendation: 2b-C). When general anesthesia is deemed necessary, careful monitoring of blood pressure, blood carbon dioxide and oxygen saturation levels is recommended (Recommendation: 2b-B) by an anesthesiologist or neurointensivist who has experience with AIS patients. (Recommendation: 2b-E)

11) Endovascular treatment should be performed in stroke centers with sufficient human and material resources, and with experience with treating patients with AIS, including: experience with intravenous thrombolysis; full-time, on-board personnel with a neurologist; full-time CT scan or MRI scan with capability of performing angiographic studies; full-time laboratory; full-time on-call board certified neurointerventionist personnel; stroke unit or neurointensive care unit; full-time, on-call neurosurgical staff. (Recommendation: 1-E).

12) Hospitals performing endovascular treatment should establish institutional, multidisciplinary protocols, and promote prospective, continuous reassessments of safety and procedural efficacy for quality assessment and improvement, including: door to neuroimaging time, door to initiation of endovascular treatment time, rate of procedural complications, rate of reperfusion (TICI $2 b-3$ ), and rate of hemorrhagic transformation. (Recommendation: 1-E).

13) Stakeholders of institutional and regional health policies (public or private) should assess local resources in order to plan for establishing a network capable of identifying and referring potential candidates for endovascular treatment to comprehensive stroke centers. (Recommendation: 1-E).
1. Turc G, Maïer B, Naggara O, Seners P, Isabel C, Tisserand M, et al. Clinical scales do not reliably identify acute ischemic stroke patients with large-artery occlusion. Stroke. 2016;47(6):1466-72. doi:10.1161/STROKEAHA.116.013144
2. Berkhemer OA, Fransen PSS, Beumer D, Berg LA, Lingsma $\mathrm{HF}$, Yoo AJ, et al. A randomized trial of intraarterial treatment for acute ischemic stroke. N Engl J Med. 2014;372(1):11-20. doi:10.1056/NEJMoa1411587 
3. Campbell BCV, Mitchell PJ, Kleinig TJ, Dewey HM, Churilov L, Yassi N, et al. Endovascular therapy for ischemic stroke with perfusion-imaging selection. N Engl J Med. 2015372(11):1009-18. doi:10.1056/NEJMoa1414792

4. Goyal M, Demchuk AM, Menon BK, Eesa M, Rempel JL, Thornton $J$, et al. Randomized assessment of rapid endovascular treatment of ischemic stroke. N Engl J Med. 2015;372(11):1019-30. doi:10.1056/NEJMoa1414905

5. Saver JL, Goyal M, Bonafe A, Diener HC, Levy El, Pereira VM et al. Stent-retriever thrombectomy after intravenous t-PA vs. t-PA alone in stroke. N Engl J Med. 2015;372(24):2285-95. doi:10.1056/NEJMoa1415061

6. Jovin TG, Chamorro A, Cobo E, Miquel MA, Molina CA, Rovira A et al. Thrombectomy within 8 hours after symptom onset in ischemic stroke. N Engl J Med. 2015;372(24):2296-306. doi:10.1056/NEJMoa1503780

7. Ferri CP, Buehler A, Flato UAP, Puglia Junior P, Fernandes JG. Endovascular thrombectomy for the treatment of acute ischemic stroke. Arq Neuropsiquiatr. 2016;74(1):67-74. doi:10.1590/0004-282X20150182

8. Goyal M, Menon BK, Zwam WH, Dippel DWJ, Mitchell PJ, Demchuk AM et al. Endovascular thrombectomy after large-vessel ischaemic stroke: a meta-analysis of individual patient data from five randomised trials. Lancet. 2016;387(10029):1723-31. doi:10.1016/S0140-6736(16)00163-X

9. Campbell BCV V, Hill MD, Rubiera M, Menon BK, Demchuk A, Donnan GA et al. Safety and efficacy of solitaire stent thrombectomy: individual patient data meta-analysis of randomized trials. Stroke. 2016;47(3):798-806. doi:10.1161/STROKEAHA.115.012360.

10. Pontes-Neto OM, Silva GS, Feitosa MR, Figueiredo NL, Fiorot $J A$, Rocha TN et al. Stroke awareness in Brazil: alarming results in a community-based study. Stroke. 2008;39(2):292-6. doi:10.1161/STROKEAHA.107.493908

11. Carvalho JJF, Alves MB, Viana GÁA, Machado CB, Santos BFC, Kanamura $\mathrm{AH}$ et al. Stroke epidemiology, patterns of management, and outcomes in Fortaleza, Brazil: a hospital-based multicenter prospective study. Stroke. 2011;42(12):3341-6. doi:10.1161/STROKEAHA.111.626523

12. Castro-Afonso LH, Abud TG, Pontes-Neto OM, Monsignore LM, Nakiri GS, Cougo-Pinto PT et al. Mechanical thrombectomy with solitaire stent retrieval for acute ischemic stroke in a Brazilian population. Clinics (São Paulo). 2012;67(12):1379-86. doi:10.6061/clinics/2012(12)06

13. Cabral NL, Magalhães PSC, Longo AL, Moro CHC, Appel H, Wille $P$ et al. Intravenous rtPA versus mechanical thrombectomy in acute ischemic stroke: a historical cohort in Joinville, Brazil. eNeurologicalSci. 2016;5:1-6. doi:10.1016/j.ensci.2016.04.002

14. Carvalho FA, Schwamm LH, Kuster GW, Bueno Alves M, Cendoroglo Neto M, Sampaio Silva G. Get with the guidelines stroke performance indicators in a brazilian tertiary hospital. Cerebrovasc Dis Extra. 2012;2(1):26-35. doi:10.1159/000339578

15. Cabral NL, Longo A, Moro C, Amaral C, Kiss H. [Epidemiology of cerebrovascular disease in Joinville, Brazil: an institutional study]. Arq Neuro-Psiquiatr. 1997;55(3a):357-63. doi:10.1590/S0004-282X1997000300002

16. Cabral NL, Gonçalves ARR, Longo AL, Moro CHC, Costa G, Amaral $\mathrm{CH}$ et al. Trends in stroke incidence, mortality and case fatality rates in Joinville, Brazil: 1995-2006. J Neurol Neurosurg Psychiatry. 2009;80(7):749-54. doi:10.1136/jnnp.2008.164475

17. Passos VMA, Ishitani LH, Franco GC, Lana GC, Abreu DMX, Marinho MF et al. Consistent declining trends in stroke mortality in Brazil: mission accomplished? Arq Neuropsiquiatr. 2016;74(5):376-81. doi:10.1590/0004-282X20160055

18. Martins SCO, Pontes-Neto OM, Alves CV, Freitas GR, Oliveira Filho J, Tosta ED et al. Past, present, and future of stroke in middle-income countries: the Brazilian experience. Int J Stroke. 2013;8 Suppl A100:106-11. doi:10.1111/ijs.12062
19. Pontes-Neto OM, Cougo-Pinto PT, Martins SCO, Abud DG. A new era of endovascular treatment for acute ischemic stroke: what are the implications for stroke care in Brazil? Arq Neuropsiquiatr. 2016;74(1):85-6. doi:10.1590/0004-282X20150191

20. Evaristo EF. Endovascular thrombectomy in acute ischemic stroke: a major breakthrough and a big challenge for Brazil. Arq Neuropsiquiatr. 2016;74(1):1-2. doi:10.1590/0004-282X20150209

21. BroderickJP, Palesch YY, DemchukAM, Yeatts SD, Khatri P, Hill MD et al. Endovascular therapy after intravenous t-PA versus t-PA alone for stroke. N Engl J Med. 2013;368(10):893-903. doi:10.1056/NEJMoa1214300

22. Ciccone A, Valvassori L, Nichelatti M, Sgoifo A, Ponzio M, Sterzi R. Endovascular treatment for acute ischemic stroke. N Engl J Med. 2013;368(10):904-13. doi:10.1056/NEJMoa1213701

23. Nogueira RG, Gupta R, Davalos A. IMS-III and SYNTHESIS expansion trials of endovascular therapy in acute ischemic stroke: how can we improve? Stroke. 2013;44(11):3272-4. doi:10.1161/STROKEAHA.113.002380

24. Maas MB, Furie KL, Lev MH, Ay H, Singhal AB, Greer DM et al. National Institutes of Health Stroke Scale score is poorly predictive of proximal occlusion in acute cerebral ischemia. Stroke. 2009;40(9):2988-93. doi:10.1161/STROKEAHA.109.555664

25. Chernyshev OY, Garami Z, Calleja S, Song J, Campbell MS, Noser EA et al. Yield and accuracy of urgent combined carotid/transcranial ultrasound testing in acute cerebral ischemia. Stroke. 2005;36(1):32-7. doi:10.1161/01.STR.0000150496.27584.e3

26. Brunser AM, Lavados PM, Hoppe A, Lopez J, Valenzuela M, Rivas R. Accuracy of transcranial Doppler compared with CT angiography in diagnosing arterial obstructions in acute ischemic strokes. Stroke. 2009;40(6):2037-41. doi:10.1161/STROKEAHA.108.542704

27. Kim JT, Park -S, Chang J, Lee JS, Choi -H, Cho -H. Proximal arterial occlusion in acute ischemic stroke with low NIHSS scores should not be considered as mild stroke. PLoS One. 2013;8(8):e70996. doi:10.1371/journal.pone.0070996

28. Rajajee V, Kidwell C, Starkman S, Ovbiagele B, Alger JR, Villablanca P et al. Early MRI and outcomes of untreated patients with mild or improving ischemic stroke. Neurology. 2006;67(6):980-4. doi:10.1212/01.wnl.0000237520.88777.71

29. Goyal M, Jadhav AP, Bonafe A, Diener H, Pereira VM, Levy E et al. Analysis of workflow and time to treatment and the effects on outcome in endovascular treatment of acute ischemic stroke: results from the SWIFT PRIME randomized controlled trial. Radiology. 2016;279(3):888-97. doi:10.1148/radiol.2016160204

30. Yoo AJ, Berkhemer OA, Fransen PSS, Berg LA, Beumer D, Lingsma HF et al. Effect of baseline Alberta Stroke Program Early CT Score on safety and efficacy of intra-arterial treatment: a subgroup analysis of a randomised phase 3 trial (MR CLEAN). Lancet Neurol. 2016;15(7):685-94. doi:10.1016/S1474-4422(16)00124-1

31. Straka M, Albers GW, Bammer R. Real-time diffusion-perfusion mismatch analysis in acute stroke. J Magn Reson Imaging. 2010;32(5):1024-37. doi:10.1002/jmri.22338

32. Saver JL, Jahan R, Levy El,Jovin TG, Baxter B, Nogueira RG et al. Solitaire flow restoration device versus the Merci Retriever in patients with acute ischaemic stroke (SWIFT): a randomised, parallel-group, non-inferiority trial. Lancet. 2012;380(9849):1241-9. doi:10.1016/S0140-6736(12)61384-1

33. Nogueira RG, Lutsep HL, Gupta R, Jovin TG, Albers GW, Walker G et al. Trevo versus Merci retrievers for thrombectomy revascularisation of large vessel occlusions in acute ischaemic stroke (TREVO 2): a randomised trial. Lancet. 2012;380(9849):1231-40. doi:10.1016/S0140-6736(12)61299-9

34. Kidwell CS, Jahan R, Gornbein J, Alger JR, Nenov V, Ajani Z et al. A trial of imaging selection and endovascular treatment for ischemic stroke. N Engl J Med. 2013;368(10):914-23. doi:10.1056/NEJMoa1212793

35. Brinjikji W, Murad MH, Rabinstein AA, Cloft HJ, Lanzino G, Kallmes DF. Conscious sedation versus general anesthesia during endovascular acute ischemic stroke treatment: a systematic review and meta-analysis. AJNR Am J Neuroradiol. 2015;36(3):525-9. doi:10.3174/ajnr.A4159 